\title{
Lectura Crítica de Kian, Azadeh (2019). Femmes et pouvoir en islam. París: Michalon Éditeur.
}

\author{
Mayra Soledad Valcarcel \\ Facultad de Filosofia y Letras, Argentina \\ mayravalcarcel@yahoo.com.ar
}

El 2019 nos recibió con un doble lanzamiento de Azadeh Kian, ${ }^{1}$ la académica especializada en sociología política, estudios feministas y de familia en Irán y "Medio Oriente". Nos presenta obras que invitan a continuar las lecturas sobre género y mundo musulmán; por un lado, Femmes et pouvoir en islam y, por el otro, Etat-nation et fabrique du genre, des corps et des sexualités: Iran, Turquie, Afghanistan en codirección con Lucia Direnberger. En esta oportunidad, nos detendremos en el trabajo que aborda la cuestión de las mujeres y el poder en el islam.

A través de los nueve capítulos que componen Femmes et pouvoir en islam, Kian reconstruye el papel de las mujeres - y en especial sus formas de transitar, ejercer y resistir el poder - en la historia de distintas sociedades y regímenes musulmanes, a través de un recorrido que inicia con el surgimiento del islam y llega hasta los feminismos islámicos en la contemporaneidad. Dedica su libro a "todas las mujeres de Medio Oriente que luchan por su dignidad y libertad" y comienza su introducción haciendo referencia al carácter o sustrato generizado de las construcciones orientalistas y neo-orientalistas que se expresan, por ejemplo, en el velo y el harem en tanto elementos de fascinación y repulsión colonial. Señala que los atentados terroristas y el ascenso del islamismo radical contribuyeron a la popularización de una perspectiva esencialista de la diferencia (la alteridad). Aquellos supuestos que platean la imposibilidad de modernización y democratización del mundo musulmán y que, a su vez, reducen a las mujeres musulmanas a víctimas sumisas del patriarcado en cuanto fenómeno intrínseco al islam. La autora enfatiza, por lo tanto, la doble opresión a las que quedan sujetas las mujeres musulmanas. Una meta-narrativa que ciertos sectores del feminismo occidental también reproducen.

Durante la presentación, Kian nos advierte sobre algunos aspectos a tener en cuenta, de los cuales destacamos tres. El primero, la distinción que realiza - siguiendo a Fred Halliday (1999)- entre islamofobia y musulmanofobia; entendiendo esta última como la racialización de los/las musulmanes/as. El segundo, cuando con un objetivo histórico comparativo nos recuerda que en Europa la construcción del Estado moderno se hizo a partir de la ausencia de las mujeres. Este punto, tal vez, despierte en quien lea el interés de poner en diálogo este texto con la obra Sexularism de Joan $\operatorname{Scott}^{2}(2009,2017)$ y pensar posibles articulaciones. Por último, señalaremos la insistencia de la autora en la necesidad de redefinir la noción weberiana de poder para así reconocer y explorar las instancias de resistencia, negociación y agencia de los/as subalternos/as. Que es aquello que, creemos, intenta visibilizar a lo largo del libro a través de la comparación entre distintos períodos y contextos islámicos. Es en este juego entre la corta y larga duración - hablándonos, por ejemplo, de mujeres emblemáticas en la historia del islam en los primeros capítulos o refiriéndose a las 
"jóvenes de la calle Enghelab"3 (Teherán) en sus conclusiones - que la autora situará la emergencia de los feminismos islámicos. Tema al que dedica el último capítulo del libro.

Kian no duda en reconocer los esfuerzos y beneficios de los feminismos islámicos en su labor de historizar y desacralizar las leyes islámicas. Especialmente en un contexto de reemergencia de los islamismos que caracteriza, al igual que los nacionalismos, como construcciones ideológicas y procesos políticos modernos en los que el control de las mujeres y su sexualidad revisten vital importancia (p. 225). En este sentido, podemos diferenciar a Kian de otras académicas y activistas (también provenientes de países de mayoría musulmana) como Wasyyla Tamzali ${ }^{4}$ y Nawal el Saadawi ${ }^{5}$ que consideran al feminismo islámico un oxímoron. En las conclusiones, la autora asevera que en las sociedades regidas por leyes islámicas el orden de género presenta mayor desventaja que la raza o la clase social; siendo reforzado por el régimen matrimonial, el discurso dominante del islam jerárquico y la subordinación social, legal y económica de las mujeres (p. 223). La yuxtaposición que advierte Kian entre estas dimensiones de opresión podría dialogar con los aportes de los feminismos afro, poscoloniales y decoloniales e incluso, tal vez, en torno a los debates sobre justicia (Young, 1990), redistribución y reconocimiento (Fraser, 2008).

Abre el primer capítulo con una pequeña descripción del contexto social (economía, organización política, status de las mujeres) de la península arábiga al momento del nacimiento del islam. Hace hincapié retomando la teoría de Lévi-Strauss (1967) y la crítica que le realiza Gayle Rubin (1998) - en las formas y relaciones matrimoniales y de parentesco. Señala los cambios que introduce el islam en contraste con la jahiliyya $b^{6}$. Realiza, además, una breve caracterización de las figuras de Khadija (primera esposa del Profeta), Aisha (otra de las esposas del Profeta) y Fátima (la única hija que sobrevivió al Profeta y símbolo central dentro de la tradición shía).

En el capítulo II, se adentra aún más en la cuestión del poder en los primeros tiempos del islam y su época de oro. Menciona distintas mujeres y personalidades históricas, por ejemplo, Umm Salama (aristócrata de la tribu Quraysh que supuestamente le cuestiona al Profeta la ausencia de las mujeres en el Corán), Sakina ${ }^{7}$ (nieta del Profeta y quien se negaba a usar el velo y emitía públicamente sus opiniones), la reina de Yemén Arwa bint Asma (1048-1138, quien recibió el título de autoridad religiosa y representante de Allah en la tierra) o Satiyya Umma el Wahid (siglo X) y Saïda Manoubia (siglo XIII) como eruditas en ciencias religiosas ( hadith y jurisprudencia). Mientras que en el siguiente capítulo se focaliza en el poder político de las mujeres bajo el Califato Fatimí (califato shí́ta con sede primero en Túnez y, luego, Egipto; que se extendió por el norte de África, el levante mediterráneo e, incluso, Sicilia entre 909-1171), la Dinastía Timúrida (dinastía turcomongol con capital en Samarcanda y posteriormente Herāt que se extendió por Asia central entre $1370 \mathrm{y}$ 1526) y el Imperio Safávida (imperio musulmán persa-iraní entre 1501-1722 con primera capital en Tabriz y la última en Isfahán). Aquí, la autora vuelve a mencionar algunas figuras políticas femeninas relevantes dentro de estos tres regímenes y, también, fuera de ellos. Y, hacia el final del mismo, destaca la práctica waqf $f^{8}$; es decir, la donación de carácter inalienable (inembargable y a perpetuidad) consagrada a una institución religiosa o de utilidad pública. Kian advierte que ésta fue una práctica muy extendida entre las mujeres de la élite durante el período safávida ya que encontraban en ella una forma de asegurar su poder, propiedades y descendencia.

El breve capítulo IV se lo dedica al harem. Nos recuerda que la palabra comparte la misma raíz del término haram que significa prohibición, pero, también, sagrado. Los relatos y retratos orientalistas reducen el harem a la clausura o la lujuria. Sin embargo, Kian lo describe como un sistema que regula las relaciones sexuales y las reglas de parentesco alrededor de un hombre; constituyéndose, además, como un espacio de vida común entre mujeres por fuera de la injerencia masculina. En otra parte del libro afirmará, compartiendo la opinión de las historiadoras Leslie Pierce (1993) y Jocelyne Dakhlia (1999), que las mujeres del harem no se encontraban recluidas y su poder era solidario a la institución política. Ilustrará con los harem durante la dinastía Qajar (Irán, 1794-1925) y con la opinión vertida por Lady Mary Wortley Montagu (1689-1762) cuando acompañó a su esposo como embajador en Turquía. Allí, luego de conocer los hamman y harem, expresó que las 
mujeres musulmanas gozaban de mayores derechos y libertades que las damas inglesas. Precisamente sobre los derechos (de casamiento, divorcio, herencia y compra-venta) de las mujeres dentro de la tradición islámica tratará el siguiente capítulo.

A partir del sexto apartado se ocupará de las transformaciones contemporáneas. Comienza con los proyectos de "modernización” en Egipto, Turquía e Irán, desde mediados del siglo XIX a principios del XX, y el rol de las mujeres en ellos. Hará referencia a los debates y la literatura sobre la educación femenina de la época y nos hablará de algunas de las pioneras feministas como la egipcia Huda Sha'arawi (una de las fundadoras de la Unión Feminista Egipcia a mediados de los años '20), la escritora turca Nezihe Muhiddin (formó parte de la fundación de la Asociación/Unión de Mujeres Turcas) y la periodista iraní Sediqeh Dowlatabadi (creadora de la revista Zaban-e-Zanan, es decir, Women's Voiceen 1919). Para profundizar en este período histórico o en algunos de los otros procesos descriptos, pueden consultarse obras - que incluso Kian retoma en este libro - como las de Nilüfer Göle (1995), Lila Abu Lughod (2002), Leila Ahmed (1992) o Afsaneh Najmabadi (2005), por citar tan sólo algunos ejemplos.

El capítulo VII continúa con los procesos de reislamización de las sociedades musulmanas a partir de los años '70 y cómo ello impactó en la regresión de los derechos de las mujeres y el derecho familiar. Hará pequeñas referencias sobre contextos tan disímiles como Pakistán, Egipto y Turquía con el objetivo de destacar dos aspectos. Primero, se refiere al modo en que la oposición islamista instrumentaliza la religión para justificar la dominación patriarcal (p. 135); encontrando eco, especialmente, en los sectores medios urbanos de origen modesto/popular. Estos movimientos poseen una doble capacidad de movilización - tanto de las clases populares como de los sectores medios instruidos/profesionales - ya que les ofrece ascenso social y político, les permite constituirse como una contra-élite que aspira a la meritocracia y se convierte, además, en un instrumento de producción de sentido colectivo (p. 140). En segundo lugar, señala la distinción entre los islamistas tradicionalistas y los islamistas liberales. Ambas alas o vertientes apoyan una economía abierta al mercado, pero mientras los primeros se afianzan en interpretaciones clásicas y creen que el Estado refuerza y debe reforzar la sharia o ley islámica(rechazando cualquier tipo de nacionalismo étnico y territorial), los segundos proponen reformas y nuevas interpretaciones (ejercicio de ijtihad) que permitan la consolidación de un Estado en el que primen los principios islámicos de justicia e igualdad social (siendo posible la reconciliación de la identidad islámica con otras formas de nacionalismo) (p. 136).

En el siguiente capítulo, la autora aborda las prácticas y sentidos de velarse y desvelarse. En primer lugar, hace referencia al pasado preislámico del pañuelo. Se remonta al código Hammurabi (1750 a. C) y su simbolización (castidad, status y segregación sexual) en las sociedades mesopotámicas, mediterráneas, el mundo persa, bizantino y greco-romano. Luego, hace una breve mención a su aparición en las aleyas coránicas y sus significaciones e interpretaciones contextuales; para finalmente advertir sobre su instrumentalización durante la colonización, así como también su reutilización estratégica en la resistencia argelina o la revolución iraní de 1979. Kian destaca, siguiendo a Myriam Cooke (2005) y Homa Hoodfar (1997), el rol que desempeña el velo en la negociación de las "identidades modernas". Reconoce la heterogeneidad existente entre quienes usan hiyab, cómo lo usan y por qué lo hacen; siendo más importante - sostiene la autora analizar las desigualdades sociales y relaciones de poder entre hombres y mujeres que no tienen su origen o fundamento ni el velo ni en la religión (pp. 177-178).

El capítulo IX, el último del libro, se aboca a los feminismos islámicos. La autora se detiene especialmente en Irán y Turquía dónde, en la década de los '90 y unos años atrás respectivamente, realizó entrevistas a feministas y mujeres destacadas del activismo y la política local. Nos cuenta, por ejemplo, sobre Shahla Sherkat (editora de la revista iraní Zanan - fundada en 1992, prohibida en 2008 y relanzada en 2013-, una publicación que se convirtió en un foro social crucial en lo que respecta a la sensibilización de las cuestiones de género y los debates para superar el binomio laico-islámico) a quien entrevistó en 1994 o Konka Kuris (feminista islámica turca que trabajaba por el diálogo entre feministas laicas y musulmanas, quien fuera desaparecida, torturada y asesinada por un grupo islamista). 
En primer término, Kian distingue los movimientos islámicos/musulmanes de los movimientos islamistas. Los primeros intentan aplicar principios religiosos en determinados espacios sociales, mientras los segundos buscan imponer un sistema totalitario y totalizante apoyándose únicamente en leyes y fundamentos islámicos (p. 183). En segundo lugar, se refiere al contexto de surgimiento de los feminismos islámicos. A saber: una escena globalizada, el fortalecimiento de los islamismos, trasformaciones estructurales (urbanización, industrialización, marginación, neoliberalismo, etc.) y falencias o contradicciones de los feminismos occidentales y de los "feminismos de Estado" (su burocratización) en los países del Magreb, Máshrek y sus alrededores. En este sentido, piensa al feminismo islámico como un feminismo híbrido que moviliza el capital simbólico del islam en determinados contextos (pp. 187-189). Sugiere que las mujeres profesionales de clase media y con orígenes populares rechazan la doble alteridad que les atribuye, por un lado, el discurso laicosecular (incluyendo el feminismo hegemónico) y, por el otro, el discurso religioso de la domesticidad; desafían y desestabilizan, por lo tanto, las identidades fijas (p. 188). Por último, afirma que las feministas islámicas contribuyen al aggiornamento del pensamiento religioso 9 a fin de construir un islam compatible con los valores democráticos (aquello que denomina en el título del capítulo como "islamizar la modernidad"), la igualdad social entre mujeres y varones, personas cis y LGTBQI ${ }^{10}$ (p. 220).

Uno de los puntos más interesantes de este capítulo - y, tal vez, del libro ya que promueve futuros debates, discusiones e intercambios con los feminismos decoloniales, por ejemplo - es la forma en que la autora redefine, recuperando los aportes de Homi Bhabha (1994), Deniz Kandiyoti (1988) y Gloria Anzaldúa (1987), los feminismos islámicos como conciencias mestizas y fronterizas. Es decir, como prácticas de hibridación que luchan contra y negocian con el patriarcado (p.214). En un trabajo anterior en el que puntualiza sobre el feminismo islámico iraní, Kian (2010) señala que este movimiento desafía la validez de un único modelo de emancipación, al mismo tiempo que nos invita a cuestionar las representaciones del islam como un cuerpo doctrinal inmutable. No duda en reconocer a las feministas islámicas como actrices sociales autónomas, pero se pregunta si sus esfuerzos y luchas podrán, sin la cooperación estatal, ser suficientes para alcanzar cambios culturales e institucionales (2010, p. 66). En este sentido, en las conclusiones del libro que aquí nos convoca, la autora nos advierte - recuperando a Eleni Varikas (2004)- que el desafío consiste en redefinir la concepción de una universalidad que reconozca la diversidad sin ceder a la tentación relativista de ignorar al poder. Esta reflexión nos invita a continuar los debates sobre universalismo, diversidad y multiculturalismo (Benhabib, 2006; Santos, 2002).

Para finalizar, Femmes et pouvoir en islam es una obra amena en su lectura y extensión. Un libro que condensa y sintetiza ciertos procesos y transformaciones históricas para brindar un panorama general sobre la temática. Es una buena elección introductoria para quienes quieran incursionar en este tópico; mientras que las personas más familiarizadas con el mismo, encontrarán que logra recapitular no sólo sucesos históricos cruciales sino también algunos trabajos emblemáticos al respecto. A nuestro parecer, la mayor riqueza del libro radica en los detalles que Kian ofrece sobre los distintos momentos de la historia iraní (que aquí, quizás, no conocemos tanto en contraste con el interés manifiesto por el mundo árabe), cuando articula su descripción con el material obtenido en las entrevistas que realizó y en las luces que parpadean en el capítulo dedicado a los feminismos islámicos.

\section{Referencias Bibliográficas}

Abu-Lughod, L. (ed.) (2002). Feminismo y modernidad en Oriente Próximo. Madrid: Ediciones Cátedra. Ahmed, L. (1992). Women and Gender in Islam: historical roots of a modern debate. New Haven: Yale University Press. Anzaldúa, G. (1987). Borderlands/ La Frontera. The New Mestiza. San Francisco: Aunt Lute Books.

Badran, M. (2012). Feminismo en el Islam. Convergencias laicas y religiosas. Madrid: Ediciones Cátedra, traducción Tania Arias. 
Barlas, A. (2019). Believing women in Islam: Unreading patriarchal interpretations of the Qur'an. Austin: University of Texas Press.

Benhabib, S. (2006). Las reivindicaciones de la cultura. Igualdad y diversidad en la era global. Buenos Aires: Katz.

Bhabha, H (1994). The Location of Culture. New York: Routledge.

Cooke, M. (2005). Critique multiple: les strategies rhétoriques feminists islamiques. L'Homme et la societé (158), 169-188.

Dakhlia, J (1999). Entrée dérobées: l'historiographie du harem. Clio, (9). Recuperado de: https://journals.openedit ion.org/clio/282

Direnberger, L. \& Kian, A. (coords.) (2019). Etat-nation et fabrique du genre, des corps et des sexualités: Iran, Turquie, Afghanistan. Aix en Provence: Presses universitaires de Provence.

Fraser, N. (2008). La justicia social en la era de la política de identidad: Redistribución, reconocimiento y participación. Revista de Trabajo, 6(4), 83-99.

Göle, N. (1995). Musulmanas y modernas. Velo y civilización en Turquia. Madrid: Talasa ediciones.

Halliday, F. (1999). Islamophobia reconsidered. Ethnic and Racial Studies, 22(5), 892-902.

Hassan, R. (1987). Equal before Allah? Woman-man equality in the Islamic tradition. Harvard Divinity Bulletin, $17(2), 2-14$.

Hoodfar, H (1997). The veil in their minds and our heads: the persistence of colonial images of muslim women. En Lloyd \& Lowe (dir.), Other Circuits: Intersections and Exchange in World Theory and Practice. Durham: Duke University Press.

Kandiyoti, D (1988). Bargaining with Patriarchy. Gender and Society, 2(3), 274-290.

Kian, A. (2010). Le féminisme islamique en Iran: nouvelle forme d'assujettissement ou émergence de sujets agissants? Critique internationale, (1), 45-66.

Lévi-Strauss, C. (1967). Les structures élémentaires de la parenté. París: Mouton et Maison des sciences de l'homme.

Najmabadi, A. (2005). Women with mustaches and men without beards: Gender and sexual anxieties of Iranian modernity. Berkeley-Londres: University of California Press.

Pierce, L. (1993). The Imperial Harem. Women and Sovereignty in the Ottoman Empire. Oxford: Oxford University Press

Rial, C. (2008). Princesas, sufragistas, islâmicas, laicas, onguistas, escritoras-a luta feminista no Irã: entrevista com Azadeh Kian-Thiébaut. Revista Estudos Feministas, 16(1), 145-169.

Rubin, G. (1998). L'économie politique du sexe. Transactions sur les femmes et systèmes de sexe/genre. Les Cabiers du Cedref, (7), 3-81.

Santos, B de Sousa. (2002). Hacia una concepción multicultural de los derechos humanos. El otro derecho, (28), 59-83.

Scott, J. (abril 2009). Sexularism. Conferencia presentada en European University Institute. Florencia, Italia. Recuperada de: http://cadmus.eui.eu/bitstream/handle/1814/11553/RSCAS_DL_2009_01 ?sequence=1

Scott, J. (2017). Sex and secularism. New Jersey: Princeton University Press.

Valcarcel, M. \& García-Somoza, M. (2017). Unidad en la Diversidad: Género y Sexualidades en tiempos del Islam transnacional. En M. Jaime (Ed.), Diversidad sexual y sistemas religiosos. Diálogos trasnacionales en el mundo contemporáneo (pp. 95-134). Lima: CMP Flora Tristán/UNMSM. Programa de Estudios de Género.

Varikas, E. (2004). Universalisme et particularisme. En Hirata et al (dirs). Dictionnaire critique du féminisme. París: PUF.

Wadud, A. (1999). Qur'an and woman: Rereading the sacred text from a woman's perspective. New York: Oxford University Press

Young, I. (1990). Justice and the politics of difference. New Jersey: Princeton University Press. 


\section{Notas}

1. Puede consultarse su trayectoria y producción en Paris Diderot, http://lcsp.univ-paris-diderot.fr/Kian-Azadeh

2. De hecho, en una entrevista que Carmen Rial le realizó a la autora, Kian sostiene que sería interesante poder traducir la obra de Scott en Irán a pesar del riesgo de censura que se corre. Por más, recomendamos leer Rial (2008).

3. Durante 2018, jóvenes mujeres iraníes se quitaron el foulard en el espacio público para manifestarse contra el uso obligatorio del mismo. Kian ilustra con un testimonio que retoma de una entrevista radial (Radio Farda) realizada a una de las involucradas el 2/2/18.

4. Abogada y militante feminista argelina que se ha desempeñado en UNESCO. Para ella, el islam es contrario a las libertades y, por ende, al feminismo. Cfr. Entrevista en Sergi D. (2011). Wassyla Tamzali: El feminismo islámico no existe. Mujeres en Red, Recuperada dehttp://www.mujeresenred.net/spip.php?article1912

5. Médica y escritora feminista egipcia. Cfr. Entrevista en: Martin, I. (2016). Nawal al Saadawi: "No defiendo ninguna religión porque todas están en contra de las mujeres", El Mundo, Recuperada de https://www.elmundo.es/internacion $\mathrm{al} / 2016 / 05 / 06 / 5729 f f 99 \mathrm{e} 2704 \mathrm{e} 3 \mathrm{f} 648 \mathrm{~b} 4634$.html

6. Período de la ignorancia. Nombre con el que se conoce la época anterior a la revelación coránica.

7. La autora nos advierte de un hecho significativo: el reconocimiento que en Irán le es otorgado a las figuras de Fátima y Zeynab (quien se enfrentó públicamente a Yazid para defender el levantamiento de su hermano Hussein asesinado y decapitado en la batalla de Karbalá), pero el olvido selectivo de Sakina.

8. Se diferencia del zakat (uno de los pilares del islam) que consiste en la limosna/caridad anual con la que todos/as los/ las musulmanes/as deben cumplir. En cambio, ésta es una práctica voluntaria/facultativa que se utiliza, por ejemplo, para construir madrasas (escuelas religiosas), hospitales u otras instituciones de bien público en favor de la comunidad de creyentes.

9. A quiénes les interese profundizar sobre las propuestas de la hermenéutica coránica con perspectiva de género pueden consultar, entre otras, las obras de Amina Wadud (1999), Riffat Hassan (1987) y Asma Barlas (2019[2002]). Y sobre las convergencias laicas y religiosas en los feminismos y movimiento de mujeres en el mundo musulmán sugerimos los trabajos de Margot Badran (2012)

10. La diversidad y disidencia sexual no es un tópico que la autora explore en el libro. Sin embargo, en la entrevista que Carmen Rial (2008) le realizó, Kian profundiza sobre este aspecto y también sobre el aborto. Por un lado, nos cuenta que en Irán la homosexualidad y el lesbianismo se castigan con pena capital y, al mismo tiempo, se permiten las cirugías de reasignación de sexo para mantener el binarismo heteronormativo. Advierte que las lesbianas forman parte de los grupos feministas, pero que no piden reivindicaciones específicas debido al contexto represivo. A quiénes les interese conocer un poco más sobre movimientos LGTBQI en el Islam, sugerimos la lectura de Valcarcel \& García Somoza (2017). Por otra parte, Kian cuenta que en Irán los métodos anticonceptivos se distribuyen gratuitamente y el aborto está permitido en el caso de mujeres casadas que corran riesgo de vida y con el consentimiento de su esposo. La legalización no se convierte en el principal tema de agenda porque las mujeres primero deben transformar el código civil para que, en lo que respecta al "precio de sangre", la vida de una mujer deje de valer la mitad de lo que vale la del hombre. 